\title{
Corrigendum: Ventral hippocampal afferents to the nucleus accumbens regulate susceptibility to depression
}

Rosemary C. Bagot, Eric M. Parise, Catherine J. Peña, Hong-Xing Zhang, lan Maze, Dipesh Chaudhury, Brianna Persaud, Roger Cachope, Carlos A. Bolaños-Guzmán, Joseph F. Cheer, Karl Deisseroth, Ming-Hu Han \& Eric J. Nestler

Nature Communications 6:7062 doi: 10.1038/ncomms8062 (2015); Published 8 May 2015; Updated 17 Jun 2015

In the original version of this Article, the middle initial of the author Joseph F. Cheer was omitted from the author information. The affiliation details for this author were also incorrect. These errors have now been corrected in both the PDF and HTML versions of the article. 